\title{
Nickel Metabolic Disorder
}

National Cancer Institute

\section{Source}

National Cancer Institute. Nickel Metabolic Disorder. NCI Thesaurus. Code C97327.

A storage disorder that results from impaired metabolism of nickel. 